The surest way to reduce production of acid by the stomach is by partial gastrectomy. This operation removes many parietal cells. Furthermore by removing the antrum, which produces gastrin, it eliminates a potent stimulus to the parietal cell. As it is a mutilating and physiologically unsatisfactory operation, the lesser procedure of vagotomy and gastric drainage is now often preferred. Vagotomy does not abolish production of gastric acid but reduces it by half to two-thirds, ${ }^{3}$ and this is usually enough. But most patients with peptic ulceration do not require surgery, and medical methods are used to control gastric acidity.

In theory an effective method of reducing gastric acid would be to diminish the activity of the parietal cells. Attempts to destroy them with gastric antibodies have met with some success in the guinea-pig. ${ }^{4}$ Again, if more was known of the biochemical events within these cells, it might be possible to block a metabolic pathway and reduce production of acid. For this reason Diamox (acetazolamide) was tried. It acts against carbonic anyhydrase, which is concentrated in parietal cells, and though it does reduce production of gastric acid ${ }^{5}$ it has not proved effective in clinical practice. Histamine and xanthines affect the functioning of parietal cells, so that further research on them might be rewarding. ${ }^{6}$ A gastrin antagonist, "antigastrin," is effective in reducing gastric acidity in the dog and is another possible approach to the problem. ${ }^{7}$

Anticholinergic drugs act by reducing vagal activity. They are fully effective only when given in doses which cause undesirable side effects such as drowsiness, dryness of the mouth, blurring of vision, and difficulty with emptying the bladder. However, they are commonly prescribed for patients with peptic ulcer, and some appear to get relief from them. In general they are disappointing in clinical practice. Though diet needs attention, it has been found that rigid "gastric" diets do not control the symptoms of duodenal ulceration, 8 and they are no better than free diets in reducing gastric acidity. ${ }^{9}$ Diets containing unusually high amounts of protein reduce acidity, ${ }^{10}$ because proteins are good buffers, a property which counteracts their ability to increase the secretion of gastric acid. This buffering action of proteins may account for the clinical effectiveness of milk.

In experimental conditions the neutralization of gastric acid with alkali relieves pain in patients with active ulcers, and the introduction of acid precipitates pain. ${ }^{11}$ But treatment with antacids does not affect the rate of healing of peptic ulcers. ${ }^{12}$ The control of gastric acidity by alkalis is thus in practice a helpful symptomatic treatment for painful ulceration but it does not appear to speed up healing.

In clinical practice the best alkali is often the one the patient likes best, either because it seems to him more effective or because the formulation is convenient. Antacid tablets are more convenient than mixtures to carry to work and if sucked

\footnotetext{
1 Hogben, C. A. M., American fournal of Medicine, 1960, 29, 726.

2 Croft, D. N., and Ingelfinger, F. J., Clinical Science, 1969, 37, 491.

Payne, R. A., Cox, A. G., Spencer, J., and Cheng, F. C. Y., British Medical fournal, 1967, 4, 456.

Hausamen, T. U., Halcrow, D. A., and Taylor, K. B., Gastroenterology, $1969,56,1062$.

Janowitz, H. D., Dreiling, D. A., Rolbin, H. L., and Hollander, F. Gastroenterology, 1957, 33, 378.

Alonso, D., and Harris, J. B., American fournal of Physiology, 1965, 208, 18.

Bedi, B. S., Gillespie, G., and Gillespie, I. E., Lancet, 1967, 1, 1240.

British Medical fournal, 1969, 3, 727 .

British Medical fournal, 1969, 3, 727.

Lennard-Jones, J. E., Fletcher, J., and Shaw, D. G., Gut, 1965, 9, 177.

1 Bonney, G. L. W., and Pickering, G. W., Clinical Science, 1946, 6, 63.

12 Doll, R., Scottish Medical fournal, 1964, 9, 183.

13 Lennard-Jones, J. E., Postgraduate Medical fournal, 1960, 36, 722.

14 Barreras, R. F., New England fournal of Medicine, 1970, 282, 1402.
}

continuously reduce gastric acidity. ${ }^{13}$ Magnesium trisilicate is not absorbed and has a laxative effect, which is useful in some patients. Aluminium hydroxide is constipating and may reduce the absorption of certain drugs such as tetracyclines. It occasionally causes weakness due to hypophosphataemia. Sodium bicarbonate is readily absorbed and can cause oedema and cardiac failure. It also causes alkalosis. The milk-alkali syndrome occurs with calcium carbonate and also sodium bicarbonate plus milk. Calcium carbonate causes hypersecretion of acid (acid rebound) as well as neutralizing acid. ${ }^{14}$ Most of these serious side effects follow intensive alkali therapy in hospital rather than the more intermittent treatment of outpatients.

We enter the 1970s little better at controlling gastric acidity by medical means than we were 30 years ago. Alkalis are still the most effective method of relieving the pain of peptic ulcer. Patients with active, painful ulcers need something in the stomach every one to two hours-but it probably does not matter if this is food, milk, or an alkali. The individual patient will decide which is most effective and convenient.

\section{Gelastic Epilepsy}

Spontaneous, unprovoked, and apparently uncontrollable laughter is a rare but recognized feature of a wide range of brain disorders. Such episodes are uncommon in patients suffering from a primary psychosis, though inane giggling does occur in the severely subnormal and in some patients with schizophrenia. Periods of inappropriate laughter, sometimes alternating with similar attacks of weeping, occur as a part of the emotional incontinence seen in patients with pseudobulbar palsy. Occasionally, too, such excessive emotional lability is observed in patients with multiple sclerosis, an observation first described in 1889 by $\mathrm{H}$. Oppenheim. ${ }^{1}$ States of abnormal excitement associated with laughter have been recorded in patients with diencephalic or hypothalamic lesions. ${ }^{2-6} \mathrm{O}$. Foerster and $\mathrm{O}$. Gagel ${ }^{3}$ provoked bursts of laughing in one of their patients when they swabbed the floor of his third ventricle while removing a papilloma of the choroid plexus under local anaesthesia. J. Purdon Martin ${ }^{7}$ has suggested that a motor centre for laughter may be situated in or near the hypothalamus, and he used the term "sham mirth" to identify this phenomenon, noting that "sham rage" in animals has commonly been evoked by the production of experimental lesions in this area.

That such attacks of laughter might be an epileptic phenomenon was first suggested by A. Trousseau ${ }^{8}$ in 1873 , and many

1 Oppenheim, H., Charité-Annalen, 1889, 14, 412

2 Schuster, P., Psychische Störungen bei Hirntumoren, klinische und statistische Betrachtungen. Stuttgart, Enke, 1902.

3 Foerster, O., and Gagel, O., Zeitschrift für Neurologie und Psychiatrie, $1933,149,312$.

Cox, L. B., Medical Fournal of Australia, 1937, 1, 742

Bailey, P., Intracranial Tumours, 2nd edn., p. 134. Springfield, Ill, Thomas, 1948

6 Cairns, H., Brain, 1952, 75, 109.

Martin, J. P., Brain, 1950, 73, 453.

Trousseau, A., Clinique Médicale de l'Hôtel-Dieu de Paris, 4th edn. p. 109. Paris, Baillière, 1873.

Druckman, R., and Chao, D., Neurology (Minneapolis), 1957, 7, 26.

10 Daly, D. D., and Mulder, D. W., Neurology (Minneapolis), 1957, 7, 189.

1 Gumpert, J., Hansotia, P., and Üpton, A., Fournal of Neurology, Neurosurgery and Psychiatry, 1970, 33, 479.

12 Druckman, R., and Chao, D., Epilepsia, 1955, 4, 61

13 Roger, J., Lob, H., Waltregny, A., and Gastaut, H., Electroencephalography and Clinical Neurophysiology, 1967, 22, 279.

14 Gibbs, F. A., and Gibbs, E. L., Atlas of Electroencephalography. Vol. 2 Epilepsy, pp. 167, 332. Cambridge, Mass., Addison-Wesley, 1952. 
case reports have since appeared describing such attacks in patients who also showed other manifestations of epilepsy. In $1957 \mathrm{R}$. Druckman and D. Chao ${ }^{9}$ described 11 patients in whom they had concluded that laughter was an epileptic manifestation, and in the same year D. D. Daly and D. W. Mulder ${ }^{10}$ coined the term "gelastic epilepsy" in describing two patients in whom laughter formed an integral part of the seizure pattern.

J. Gumpert, P. Hansotia, and A. Upton ${ }^{11}$ recently described a patient with retinitis pigmentosa who experienced stereotyped and repetitive attacks of abrupt onset characterized by involuntary movements of the limbs, adversion of the head, increased tone on the right side of the body, and short attacks of high, cackling, monotonous laughter. While under observation she also had a single grand mal seizure. Electroencephalographic recordings showed little electrical activity during the periods of laughter, which generally lasted for only a few seconds, but these episodes were interspersed with bursts of irregular, high-voltage, generalized slow-wave activity and spikes. The patient got better rapidly after treatment with intravenous diazepam, and, though she later suffered further episodes of laughter, continuation of this treatment produced sustained improvement. Gumpert and colleagues noted that others $^{12} 13$ have described similar electroencephalographic abnormalities in cases of gelastic epilepsy, though some reports of previous cases have described 14 and $6 \mathrm{c} / \mathrm{s}$ positive spike patterns ${ }^{14}$ and features resembling hypsarrhythmia. ${ }^{9}$

Roger and his colleagues ${ }^{13}$ found that some of their patients with epileptic attacks associated with laughter or smiling had clear evidence of temporal lobe epilepsy, and in one of the patients described by Daly and Mulder $^{10}$ a left temporooccipital oligodendroglioma was found. Despite these observations, however, the evidence for a hypothalamic origin for attacks of gelastic epilepsy seems to be substantial. Gumpert and colleagues ${ }^{11}$ were unable to draw any final conclusions about the site of origin of the epileptic discharge in their patient; but without question uncontrollable laughing may be an epileptic phenomenon, and it is plain that the effects of diazepam should be tested in further cases of this rare condition.

\section{Infant Mortality and Population Structure}

In countries with accurate vital statistics it has long been recognized that more males than females are born alive. Among liveborn infants in Great Britain in 1968 there were 106 males to every 100 females, a ratio which has persisted for a long time. In years gone by this preponderance of males at birth became a preponderance of females by the time the reproductive period had been reached. For the 100 years up to the second world war there were on average in the British population 92 males aged 15-49 years per 100 females of the same age. This reversal of the birth sex ratio was due to the higher mortality among males from disease and violence in early life, to emigration, and to wars. But as mortality in infancy and childhood has fallen the sex ratio in young adult

\footnotetext{
${ }^{1}$ Abramowicz, M., and Barnett, H. L., American Fournal of Diseases of
Children, 1970, 119, 314.
}

life has come progressively closer to that at birth, and in 1968 there were in Great Britain 103 males to every 100 females aged $15-49$ years.

As a general corollary to those figures it might have been expected that improvement in infant mortality-that is, in the first year of life-would have benefited the more vulnerable male rather than the female. But this is not the case. Taking 13 countries in the world for which statistics are available M. Abramowicz and H. L. Barnett ${ }^{1}$ have shown that during the 35 years following 1915 a fall in infant mortality was associated with an increase, not a decrease, in the number of male deaths in infancy relative to the number of female deaths. Thus at an infant mortality rate of about 150 per thousand live births the ratio of male to female deaths was $1 \cdot 1$ to 1 , whereas at an infant mortality rate of 30 per thousand live births the ratio was 1.3 to 1 .

This trend in infant mortality is having little effect on the proportions of males and females in the young adult population in Britain. Deaths in infancy reflect the mortality. situation in only one of the 15 years prior to the reproductive period. More important, however, is the conclusion that, when infant mortality rates reach the low level now seen in most of the developed countries of the world, relative changes in male and female death rates in infancy have an insignificant effect on the sex ratio of the future adult population.

\section{"Psychological Medicine"}

This week a new specialist journal appears for the publication of papers on research in clinical psychiatry and the allied sciences. ${ }^{1}$ Entitled Psychological Medicine, it is edited by Professor Michael Shepherd, who holds the chair of epidemiological psychiatry at the Institute of Psychiatry in the University of London. The British Medical Association is publishing it as one of the specialist journals, of which there are now 17, associated with the British Medical fournal. The assistant editors are Professor J. L. Gibbons, of the University of Southampton, and Professor K. Rawnsley, of the Welsh National School of Medicine, Cardiff. In addition to psychiatrists the journal's editorial board ${ }^{2}$ includes experts in a variety of cognate branches of medicine and science.

Research with a bearing on clinical psychiatry has had as high a growth rate as any in recent years, with the result that delays and difficulties are apt to impede the flow of information from author to reader. The cynic may wonder whether this is not a good thing-but psychiatrists on the whole are not cynical people. The aim of the new journal, therefore, is to offer reasonably prompt publication to papers of high scientific standard. The need for it has been tested by thorough inquiry over several years among potential readers and authors.

\footnotetext{
Annual subscription rate $£^{3} 15$ s. in the United Kingdom and Republic of Ireland, and $£^{4} 4 \mathrm{~s}$. overseas (U.S.A. \$11; Canada \$12). Inquirie to Subscription Manager, Psychological Medicine, B.M.A. House, Tavistock Square, London WC1 H9JR

2 Dr. G. W. Ashcroft, Dr. J. A. N. Corsellis, Dr. J. W. B. Douglas, Professor J. G. Gibson, Professor D. V. Glass, Professor H. Gwynne Jones, Professor G. W. Harris, Dr. M. Lader, Sir Aubrey Lewis, Dr. W. A. Lishman, Professor W. M. Millar, Professor W. D. M. Paton, Professor L. S. Penrose, Dr. Cyril Rashbass, Dr. Geoffrey Rose, Professor G. S. Penrose, Dr. Cyril Rashbass, Dr. Geofrey Rose, Professor Kraüpl Taylor, Professor J. Tizard, Dr. Ian Sutherland, Dr. J. K. Wing, and Professor O. C. Zangwill.
} 